\title{
Seroepidemiological survey of transmissible infectious diseases in a Portuguese prison establishment
}

\section{Authors}

Nuno Miguel da Silva Marques $^{1}$

Renata Margalho

Maria João $\mathrm{Melo}^{3}$

José Gabriel Saraiva da Cunha $^{4}$

António Abel Meliço-

Silvestre ${ }^{5}$

${ }^{1} \mathrm{MD}$; Physician, Infectious Diseases Clinic, University Hospitals of Coimbra, EPE, Portugal

${ }^{2} \mathrm{MSc}$; Clinical Psychologist, Infectious Diseases Clinic,

University Hospitals of

Coimbra, EPE, Portugal

${ }^{3}$ LGSW, Social Worker

of Regional Prison

Establishment of Coimbra,

Portugal

${ }^{4} \mathrm{MD}, \mathrm{PhD}$; Head of

Infectious Diseases Clinic,

University Hospitals of

Coimbra, EPE; Professor of

Coimbra's Medical School,

Portugal

${ }^{5} \mathrm{MD}, \mathrm{PhD}$; Head of

Infectious Diseases

Department, University

Hospitals of Coimbra, EPE;

Professor of Coimbra's

Medical School, Portugal

Submitted on: 09/01/2010 Approved on: 09/29/2010

Correspondence to:

Nuno Marques

Infectious Diseases Clinic

University Hospitals of

Coimbra, Praceta

Prof. Mota Pinto,

Coimbra, Portugal

3000-075

lusonmar@hotmail.com

Financial Support: This study was funded by a grant of Portuguese Society of Clinical Microbiology and Infectious Diseases Abbott Virology.

We declare no conflict of interest.

\begin{abstract}
A cross-sectional study was conducted in 151 (71.6\%) of 211 male inmates of a regional Portuguese prison in order to establish the seroprevalence for viral hepatitis (HAV, HBV, HCV), human immunodeficiency virus (HIV), syphilis and herpes simplex virus (HSV-1 and HSV-2) and to analyze some psychosocial and criminal characteristics. Mean age was 34 years. Anti-HAV was positive in $69.5 \%(n=105)$ and in 34.4\% $(n=52)$ for anti-HCV. One $(0.7 \%)$ person had HBsAg and $29(19.2 \%)$ had laboratory markers of past HBV infection. Non-immune inmates for HBV were $40.4 \%(n=61)$. Syphilis was diagnosed in $6.0 \%(n=9)$. The rate of HIV infection was $6.6 \%(n=10$; all HIV-1). The seropositivity of HSV-2 was $19.9 \%(n=30)$ and of HSV-1 was $82.1 \%(n=124)$. Alcohol dependence was reported by $26.5 \%(\mathrm{n}=40)$. Excluding tobacco and prescription medication, $73.5 \%(\mathrm{n}=111)$ reported drug use in prison. The most commonly used drugs were: cannabis $(100 \% ; n=111)$ followed by heroin $(56.7 \% ; n=63)$. Anti-HCV rate was noteworthy. The HIV infection rate $(6.6 \%)$ in this regional prison is at least 13 to 22 times greater than in general population. As the inmate return to the community increases the risk of disease exposure for the general population, early detection and counseling is urgently needed for prisoners.
\end{abstract}

Keywords: mass screening; communicable diseases; prisons; drug users.

[Braz J Infect Dis 2011;15(3):272-275] @Elsevier Editora Ltda.

\section{INTRODUCTION}

Prison inmates are reported to have higher rates of transmissible infectious diseases, particularly blood-borne virus and sexually transmitted infections (STI) than the general population. It may be related to risk factors before incarceration such as low socioeconomic status, poor access to health care, poor household sanition, high-risk sexual behaviors and injection drug use. Following incarceration, additional risk factors, such as crowded living conditions, sexual harassment, psychological stress, non-professional tattooing or body piercing, and poor ventilation systems contribute to a further increase of infectious diseases risk.

The prevalence rate among incarcerated individuals is 8-10 times higher for human immunodeficiency virus (HIV), 9-10 times higher for hepatitis $\mathrm{C}$ (HCV), and 4-17 times higher for tuberculosis than in the surrounding community. ${ }^{1}$ Men entering prison have high risk behavior for STI, including high frequencies of injection drug use, needle sharing, and unprotected sex with multiple and high risk partners. The strong relationship among alcohol and drug use, incarceration and STI prevalence has been highlighted. ${ }^{2}$ Drug users are vastly over-represented in prison. Moreover, imprisoned populations are dynamic, with a great deal of frequent in and out of prisoners, prison staff, and visitors. These two particularities of imprisoned populations, a high proportion of drug use and a high turnover of inmates, contribute to the spread of blood-borne viruses among prisoners and the community. Since most of blood-borne viruses and/or STI (hepatitis B, hepatitis C, HIV, syphilis and herpes simplex virus) are asymptomatic, there is a need for routine screening.

The situation regarding HIV and other blood-borne and/or STI in prisons in Portugal is unclear as accurate data are limited and difficult to access. Therefore, studies assessing the real situation of these infections in the prison environment are urgently needed. 
STI education is the most widely used HIV prevention intervention in prisons and only a small but increasing number of countries provide methadone maintenance programs, needle and syringe programs, or condoms to prisoners. However, entry into the correctional system also offers an important opportunity for primary, secondary and tertiary prevention strategies. One should not forget that for some detainees, the prison may be the first exposure to primary health care. Prison-based screening programs provide a unique circumstance for early intervention: for the individual through detection and treatment, and for the community through interrupting disease transmission when prisoners return to community.

The authors conducted a seroepidemiological survey of viral hepatitis (hepatitis A-HAV, hepatitis B-HBV and hepatitis C-HCV), HIV, syphilis and herpes simplex virus (HSV-1, HSV-2) in a male adult regional prison (Regional Prison Establishment of Coimbra, Portugal) which has an official total number of 220 inmates. This kind of prison is meant for prisoners condemned up to 8 years. There is a clinical facility within the prison with a doctor, nurses and social workers; however the clinical monitoring of infectious diseases is carried out in hospitals of the National Health Service. All inmates diagnosed with one or more of the previous infections and without any prior infectious diseases were referred to our infectious disease clinic. Unfortunately, this prison establishment was closed in June 2009 and all inmates were transferred out to other prison facilities. The main reasons for this process were related to lack of appropriate conditions such as overcrowding and health facilities. Nevertheless, the majority of those referred were kept in our clinic.

\section{METHODS}

This cross-sectional study was conducted during December 2007 to January 2008 and March to June 2008. All participants signed an informed consent and provided a blood sample. All epidemiological and demographic data were collected through an interview performed by a psychologist and a medical doctor. The following serological techniques were used: CMIA (chemiluminescent microparticle immunoassay) for viral hepatitis and HIV; RPR (rapid plasma reagin) and TPPA (Treponema pallidum particle agglutination assay) for syphilis and ELISA (enzyme-linked immunosorbent assay) for HSV. HIV positive serology was always confirmed by Western blot.

\section{RESULTS}

All prisoners were asked to take part in the study. During the first period, 121 from 146 inmates accepted to be screened and during the second period, from 65 inmates that were not imprisoned in the first period, 30 entered the study. Therefore, 151 (71.6\%) of 211 inmates participated in this survey.
Table 1. Demographic characteristics of the study sample

\begin{tabular}{lcc} 
Characteristics & $\mathbf{n}=\mathbf{1 5 1}$ & $\%$ \\
Age, mean (SD), \\
[min, max] & $\mathbf{3 4 . 1} \mathbf{( 1 0 . 8 ) , [ 1 9 - 7 5 ]}$ & \\
\hline Ethnicity & & \\
$\quad$ White & & \\
$\quad$ Black & 52 & $60.9 \%$ \\
\hline Marital status & 59 & $39.0 \%$ \\
$\quad$ Single & & \\
$\quad$ Divorced & 86 & $57.0 \%$ \\
$\quad$ Married & 44 & $29.1 \%$ \\
$\quad$ Widowed & 8 & $5.3 \%$ \\
\hline Education level & 13 & $8.6 \%$ \\
$\quad$ Illiteracy & & \\
$\quad$ Elementary & 18 & $11.9 \%$ \\
$\quad$ High school & 69 & $45.7 \%$ \\
Vocational & 55 & $6.0 \%$
\end{tabular}

The socio-demographic profile, shown in Table 1, revealed a mean age of 34 years ranging from 19 and 75 years; $60.9 \%$ were Caucasian, $57 \%$ were single and $45.7 \%$ had elementary education.

The majority $(71.5 \% ; \mathrm{n}=108)$ of the inmates had a history of previous incarceration and their crime typology was as follows: assault with intent to endanger life $(n=10)$, attempted kidnapping and burglary $(n=1)$, theft $(n=20)$; criminal fraud $(\mathrm{n}=2)$, drug traffic $(\mathrm{n}=78)$ and driving under the influence of alcohol $(n=40)$.

Most of the inmates admitted substance dependency of cannabis $(\mathrm{n}=111 ; 73.5 \%)$, heroin - a semi-synthetic opiate $(\mathrm{n}=63 ; 41.7 \%)$, alcohol $(\mathrm{n}=40 ; 26.5 \%)$ and methadone $-\mathrm{a}$ fully synthetic opioid ( $\mathrm{n}=19 ; 12.6 \%)$. Tobacco and prescription medication were not considered. Regarding illicit drug use in prison, cannabis and/or heroin were the only drugs reported by $73.5 \%(n=111)$ of inmates. The drug use pattern before and after incarceration is shown in Table 2 .

Although there were no cases of new onset of drug addiction after detention, the pattern of drug use changed while in prison. Above all, heroin use increased with reclusion, but all heroin addicts denied its injection use in prison.

Regarding sexual behavior, there was an almost unanimous preponderance of heterosexual sexual orientation (98.7\%; $\mathrm{n}=149$ ), except for two that did not respond. Before incarceration, $75.5 \%(\mathrm{n}=114)$ had multiple sex partners and the frequency of condom use was as follows: frequently $(3.3 \% ; n=5)$, rarely $(30.5 \% ; n=46)$ and never $(66.2 \%$; $\mathrm{n}=100$ ). When questioned about condom use during reclusion, all inmates replied that they have not had sex with anyone. 


\begin{tabular}{|c|c|c|c|c|}
\hline $\begin{array}{l}\text { Drug use: illicit drugs } \\
\text { Age at the beginning of consumption, mean [min, max] }\end{array}$ & & & $\begin{array}{c}n=111(73.5 \%) \\
15,[12-24]\end{array}$ & $\%$ \\
\hline Type of drug $(n=111)$ & \multicolumn{2}{|c|}{ Before incarceration } & \multicolumn{2}{|c|}{ After incarceration } \\
\hline Cannabis & 92 & $82.9 \%$ & 111 & $100 \%$ \\
\hline Heroin & 14 & $12.6 \%$ & 63 & $56.7 \%$ \\
\hline Others & 5 & $4.5 \%$ & 0 & $0 \%$ \\
\hline \multicolumn{5}{|l|}{ Setting of drug use (before incarceration) } \\
\hline Social & 87 & & $78.4 \%$ & \\
\hline Familiar & 20 & & $18.0 \%$ & \\
\hline Alone & 4 & & $3.6 \%$ & \\
\hline \multicolumn{5}{|l|}{ Route of heroin administration in prison $(n=63)$} \\
\hline Smoking & 16 & & $25.3 \%$ & \\
\hline Sniffing/Snorting & 47 & & $74.6 \%$ & \\
\hline \multicolumn{5}{|l|}{ Frequency of heroin administration in prison $(n=63)$} \\
\hline Weekly & 27 & & $42.9 \%$ & \\
\hline Monthly & 9 & & $14.3 \%$ & \\
\hline Daily & 18 & & $28.6 \%$ & \\
\hline No response & 9 & $14.3 \%$ & & \\
\hline
\end{tabular}

After imprisonment, $43.0 \%(\mathrm{n}=65)$ reported receiving a tattoo and $3.3 \%(n=5)$ a piercing.

The serological testing revealed the following results:

$\mathrm{HCV}$ infection: The overall anti-HCV prevalence was $34.4 \%(n=52)$, which was noteworthy.

Concerning HBV serological testing, three serostatus categories were established: past infection, all with anti$\mathrm{HBc}$-positive (includes people who were infected in the past and have either anti-HBc positive plus anti-HBs positive or isolated anti-HBc positive), chronic infection (anti$\mathrm{HBc}$-positive and HBsAg-positive) and no immunity (anti-HBc-negative, anti-HBs-negative and HBsAg-negative). Therefore, $H B V$ serostatus were as follows: past infection $(19.2 \% ; n=29)$, chronic infection $(0.7 \% ; n=1)$ and no immunity $(40.4 \% ; \mathrm{n}=61)$. Serological evidence of vaccination was present in $39.7 \%(\mathrm{n}=60)$.

HAV immunity was observed in $69.5 \%(\mathrm{n}=105)$ of inmates.

HIV infection: Anti-HIV prevalence was $6.6 \%(\mathrm{n}=10)$, all HIV-1 positive. The majority $(80 \% ; n=8)$ were co-infected with HCV.

Syphilis: This STI was diagnosed in $6.0 \%(\mathrm{n}=9)$, all with latent syphilis.

HSV infection: Genital HSV infection is life-long with rare to frequent recurrences of symptomatic and asymptomatic genital shedding of 2 serotypes of virus; most commonly HSV-2, and sometimes HSV-1. The seropositivity of HSV-2 was $19.9 \%(n=30)$ and of HSV-1, 82.1\% $(n=124)$. None of the inmates had active genital lesions.

\section{DISCUSSION}

Because of the absence of a vaccine, further reductions in the number of new HCV cases will depend on harm reduction education. HCV prevalence is comparable to that among other prison populations in Portugal, Spain and USA..$^{3-6}$ Nevertheless, it is 17 to 23 times higher than the Portuguese general population (1.5\%-2.0\%).

Vaccination for HAV and HBV should be offered to all non-immunes, although vaccination coverage for HBV (39.7\%) was adequate as well as the immunization rate for HAV (69.5\%). Concerning the latter, most of incarcerated persons have risk factors for infection (drug use, homosexual sex); for that reason vaccination is essential for preventing acute hepatitis A outbreaks in prisons. In this study, the immunization rate for HAV, either natural or by vaccination, is one of the highest in prison settings. The prevalence of prior HAV infection among USA incarcerated persons is estimated at $22 \%-39 \% .{ }^{6}$ Chronic HBV infection prevalence $(0.7 \%)$ in this survey was slightly lower than the one described among USA prison inmates (1.0\%-3.7\%). ${ }^{6}$ Studies have shown that achieving high vaccination coverage is both feasible and cost-effective and treating appropriately screened individuals has been considered a reasonable expenditure for correctional facilities?

Portugal has the second highest HIV incidence rate (251.1 cases per million inhabitants) within the context of the 52 European countries. ${ }^{8} \mathrm{HIV}$ infection rate $(6.6 \%)$ in Coimbra Regional Prison is at least 13 to 22 times greater 
than in the Portuguese general population (0.3\%-0.5\%). It is similar to the prevalence found in some of the French prisons (6\%) and lower than the rates reported in the USA (up to $17 \%$ for prisons in New York) and Spain (19\%) correctional facilities. ${ }^{4,5,9,10}$ Nonetheless, in the USA, HIV seroprevalence among prisoners was $1.1 \%-1.9 \%$ in $2003 .{ }^{11}$ According to the National Program for Prevention and Control of HIV/AIDS infection, it is estimated that the prevalence of HIV infection in the incarcerated Portuguese population is $10.2 \%$ and the HCV infection rate is $29 \%$, with $56.8 \%$ of HIV-infected inmates co-infected by HCV. ${ }^{8}$ Being diagnosed with a sexually transmitted disease puts a person at increased risk for contracting HIV and serves as an indicator of HIV risk behavior. Therefore, the rate of syphilis (6.0\%), similar to HIV rate, is significant as well as the high prevalence of seropositivity for HSV. The medical literature reports an increased risk of HIV acquisition estimated at 2 to 4 times greater when HSV is present, particularly in men who have sex with men. ${ }^{12}$ In the USA, the rate of syphilis diagnosed in male prison inmates, during 2004, was $2.7 \%$, lower than the rate found in our study. ${ }^{13}$ To our knowledge, studies concerning seroprevalence of HSV infection in prison are scarce. Seropositivity of HSV-2 was $19.9 \%$, which is important since HSV-2 is the primary cause of genital herpes, transmitted primarily through sexual contact.

Sexual risk behavior compounded by addictive problems such as alcoholism or drug abuse is frequent and increases with incarceration. Heroin use increased 4.5 times with imprisonment. The report of no drug injecting observed in this study may be related to some particularities of this kind of establishment. Besides being a prison with short capacity, due to a punishment and violence dynamic, inmates may suffer retaliations if syringes or other injecting paraphernalia are found in their cells, which are being constantly supervised by prison guards. Additionally, it is reported that intravenous drug users are more likely to stop injecting than to continue while in prison. ${ }^{14}$ Approximately one in four injectors reported continuing to inject drugs while in prison inthe UK. ${ }^{14,15}$ A high prevalence (43\%) of tattooing in prison was found. Tattooing may provide a link between non-injecting and injecting inmates, thus enabling bloodborne infections to be disseminated. Furthermore, it is well-known that addictive behavior is associated to crime with high relapse rates. Drug use implies alteration of consciousness and a self-perception of loss of control. Most of the inmates also had high prevalence of sexual risk behavior, particularly sexual intercourse without condoms and multiple sex partners. Although they unanimously have denied having sex in prison, condoms should be supplied to them. This epidemiological study represents a disturbing reality and is a public health issue. Over $70 \%$ of the prison inmates had been previously incarcerated illustrating the close tie between civilian and incarcerated populations.
As the inmate return to the community increases the risk of disease exposure for the general population, early detection and counseling is urgently needed for prisoners. We must act to change behaviors through cognitive and emotional instruments and consider skills, personality traits and social support.

Effective health promotion requires both human and financial investment in the field of public health. Correctional facility-based immunization programs, infectious disease screening and treatment, and harm-reduction efforts are essential components of any strategy for the control of communicable diseases.

\section{REFERENCES}

1. Hammett TM, Harmon P, Maruschak L. 1996-1997 Update: HIV/AIDS, STDs and TB in correctional facilities. Cambridge, MA: ABT Associates 1999.

2. Altice FL, Mostashari F, Selwyn PA et al. Predictors of HIV infection among newly sentenced male prisoners. J Acquir Immune Defic Syndr Hum Retrovirol. 1998; 18:444-53.

3. Passadouro R. Prevalence infections and risk factors due to HIV, Hepatitis B and C in a prison establishment in Leiria. Acta Med Port. 2004; 17(5):381-4.

4. Saiz de la Hoya P, Bedia M, Murcia J, Cebriá J, Sanchez-Payá J, Portilla J. [Predictive markers of HIV and HCV infection and co-infection among inmates in a Spanish prison.] Enferm Infecc Microbiol Clin. 2005; 23(2):53-7. Spanish.

5. Grupo Castellano-Leones para el estudio de infeccion VIH en prisiones. Study of cases of HIV infection in Castile-Leon prisons. Rev Clin Esp. 2001; 201(5):249-55.

6. Centers for Disease Control and Prevention. Prevention and control of infections with hepatitis viruses in correctional settings. MMWR Morb Mortal Wkly Rep. 2003; 52:1-35.

7. Centers for Disease Control and Prevention. Hepatitis B vaccination of inmates in correctional facilities-Texas, 2000-2002. MMWR Morb Mortal Wkly Rep. 2004; 53:681-3.

8. Directorate-General of Health. Health in Portugal 2007 - Lisbon: Directorate-General of Health, 2007.

9. Rotily M, Vaisse V, Bourliére M, Pujol AG, Rousseau S, Obadia Y. HBV and HIV screening, and hepatitis B immunization program in the prison of Marseille, France. Int J STD AIDS 1997; 12:753-9.

10. Griffin MM, Ryan JG, Briscose VS, Shadle KM. Effects of incarceration on HIV-infected individuals. J Natl Med Assoc. 1996; 88(10):639-44.

11. Maruschak L. HIV in Prisons, 2003. Washington: U.S. Department of Justice, Bureau of Justice Statistics; September 2005

12. Wald A, Link k. Risk of human immunodeficiency virus infection in herpes simplex virus type 2-seropositive persons: a meta-analysis. J Infect Dis. 2002; 185:45-52.

13. Centers for Disease Control and Prevention. Sexually transmitted disease surveillance 2004. US Department of Health and Human Services, Atlanta, GA. 2005.

14. Shewan D, Gemmell M, Davis JB. Behavioural change amongst drug injectors in Scottish prisons. Soc Sci Med. 1994; 39(11):1385-6.

15. Dolan KA. Drug injectors in prison and the community in England. Int J Drug Policy 1993; 4(4):179-83. 